\title{
TMJ Disorders: Future Innovations in Diagnostics and Therapeutics
}

\author{
Sunil Wadhwa, D.D.S., Ph.D.; Sunil Kapila, B.D.S., M.S., Ph.D. \\ Abstract: Because their etiologies and pathogenesis are poorly understood, temporomandibular joint (TMJ) diseases are diffi- \\ cult to diagnose and manage. All current approaches to treatments of TMJ diseases are largely palliative. Definitive and rational \\ diagnoses or treatments can only be achieved through a comprehensive understanding of the etiologies, predisposing factors, \\ and pathogenesis of TMJ diseases. While much work remains to be done in this field, novel findings in biomedicine and develop- \\ ments in imaging and computer technologies are beginning to provide us with a vision of future innovations in the diagnostics \\ and therapeutics of TMJ disorders. These advances include the identification and use of local or systemic biomarkers to diagnose \\ disease or monitor improvements in therapy; the use of imaging technologies for earlier and more sensitive diagnostics; and the \\ use of biomedicine, biomimetics, and imaging to design and manufacture bioengineered joints. Such advances are likely to help \\ to customize and enhance the quality of care we provide to patients with TMJ disorders.
}

Dr. Wadhwa is the Charles J. Burstone Assistant Professor, Division of Orthodontics, School of Dental Medicine, University of Connecticut Health Center; Dr. Kapila is the Robert W. Browne Professor and Chair, Department of Orthodontics and Pediatric Dentistry, School of Dentistry, University of Michigan. Direct correspondence and requests for reprints to Dr. Sunil Kapila, Department of Orthodontics and Pediatric Dentistry, School of Dentistry, University of Michigan, 1011 North University Avenue, Ann Arbor, MI 48109-1078; 734-647-8750; skapila@umich.edu.

This work was supported in part by grants RO1 DE DE018455 and KO2 DE00458 to Dr. Kapila and K-22 DE017193 and American Association of Orthodontists Foundation Faculty Development Award to Dr. Wadhwa.

Key words: temporomandibular joint, degenerative joint disease, pathogenesis, imaging, biomedicine, tissue engineering

$\mathrm{T}$ The phrase "temporomandibular disorders (TMDs)" is a collective term embracing a number of clinical problems that involve the masticatory musculature, the temporomandibular joint (TMJ) and associated structures, or both. These disorders are accompanied by pain in the masticatory muscles, in the TMJ, and in the associated hard and soft tissues. Other symptoms include limitation or deviation in the mandibular range of motion, TMJ sounds, and/or headaches and facial pain..$^{1-6}$ Symptoms of TMDs occur in approximately 6 to 12 percent of the adult population or approximately ten million individuals in the United States. ${ }^{7,8}$ It is estimated that $17,800,000$ workdays are lost each year for every $100,000,000$ full-time working adults in the United States due to disabling TMDs.

The epidemiologic predilection of TMDs in women is striking. In the general population, TMDs are two times more prevalent in women than in men, whereas in patient populations these diseases have a female-to-male preponderance as high as 10:1.,8,9 Furthermore, unlike similar diseases of other joints, which also have a greater female predilection but occur postmenopausally, ${ }^{10}$ a large proportion of women with TMDs are between eighteen and forty-five years of age. ${ }^{11,12}$ The reasons for this marked sexual dimorphism and age distribution remain unclear.
Of the patients with TMDs, approximately 80 percent present with signs and symptoms of joint disease, including disc displacement, arthralgia, osteoarthrosis, and osteoarthritis, ${ }^{13,14}$ indicating that an understanding of the underlying pathobiology of diseases of the TMJ itself would be beneficial to a large proportion of patients with TMDs. These degenerative TMJ diseases are characterized by an imbalance in the synthesis and degradation of matrices, which are mediated by chondrocytes and fibrochondrocytes in the cartilage and fibrocartilages of the TMJ, resulting in a progressive loss of extracellular matrix components of the articular cartilage and/or subchondral bone. Due to a poor understanding of the etiology or pathogenesis of these diseases and the lack of definitive diagnostic or therapeutic approaches, patients often have to tolerate symptoms, including debilitating pain, that substantially impact their quality of life over extended periods of time. While little is known about the etiology or factors that predispose to degenerative diseases of the TMJ, recent findings employing both basic biomedicine and new imaging and computer technologies are beginning to provide important insights that may help in deriving rational diagnostic and therapeutic strategies. The focus of this review is to provide a basic foundation on degenerative disorders of the TMJ 
and to discuss current biomedical and technological advances in the understanding of these conditions. The implications of these advances for prevention, diagnostic, and therapeutic strategies are described.

\section{Anatomy of the TMJ}

The TMJ is a ginglymoarthroidal joint: that is, a joint that is able to have both rotational and translational movements. The TMJ is formed by the mandibular condyle fitting into the mandibular fossa of the temporal bone (Figure 1A). Separating these two bones from direct contact is the articular disc. The articular portion of the disc is comprised of dense fibrous connective tissue devoid of any nerves and vessels; conversely, the posterior attachment of the disc is richly vascularized and innervated. The disc is attached to the condyle both medially and laterally by collateral ligaments. Rotational movement occurs between the condyle and the inferior surface of the disc during early opening (the inferior joint space), and translation takes place in the space between the superior surface of the disc and the fossa (the superior joint space) during later opening. Synovial fluid within the joint facilitates movement within the joint; it also serves as a medium for the transportation of nutrients to and waste products from articular surfaces.

The mandibular condylar cartilage is comprised of four distinct layers or zones (Figure 1B). The most superficial layer is called the articular zone or superficial zone. It is found adjacent to the joint cavity and forms the outermost functional surface. This zone is responsible for dissipating shearing and frictional loads generated by jaw functions. One way it is able to accomplish this is by the expression of a protein named superficial zone protein (SZP). In the TMJ, SZP localizes to the superficial layer of the mandibular condylar cartilage and the TMJ disk. ${ }^{15}$ SZP is a large proteoglycan that is synthesized and secreted into synovial fluid. It is known to function as a boundary lubricant in articular joints by reducing the coefficient of friction of the mandibular condylar cartilage surface and the strain energy of the synovial fluid. ${ }^{16}$
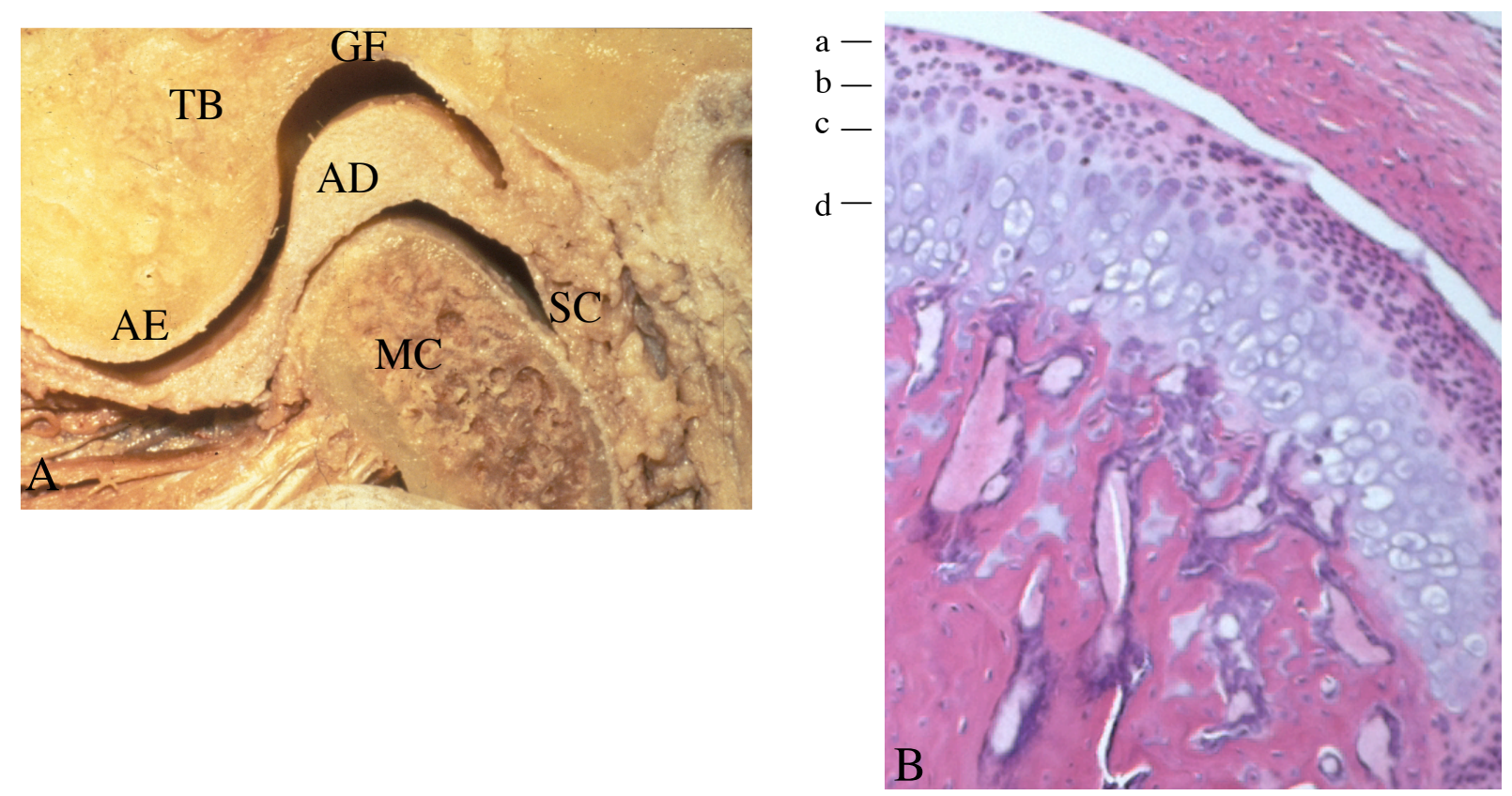

Figure 1. Gross anatomy, organization, and histology of the TMJ

A. Skeletal components that make up the TMJ include the glenoid fossa (GF) and articular eminence (AE) of the temporal bone (TB), the mandibular condyle (MC), and the intervening articular disc (AD), which are surrounded by the synovial capsule (SC).

B. Histology of the mandibular condylar cartilage demonstrates four distinct zones: a-articular, b-polymorphic or proliferative, c-flattened or chondroblastic, and d-hypertrophic. 
The second zone is the polymorphic or proliferative zone. This zone is mainly cellular with undifferentiated mesenchymal tissue. The cartilage cells in this layer are large and enclosed in lacunae. There is no organization of formation or arrangement of cartilage cells in this layer. This tissue is responsible for the proliferation of articular cartilage in response to the functional demands placed on the articular surfaces during loading and unloading. This zone is characterized by the expression of Sox-9 and the absence of the expression of Collagen type II. ${ }^{17}$ The third zone is the flattened or chondroblastic zone. The cartilage cells in this region are highly mature. The cartilage cells have not yet lost their ability to proliferate. ${ }^{18}$ In this zone, the collagen fibrils are arranged in bundles in a crossing pattern. The cartilage appears in a random orientation, providing a threedimensional network that offers resistance against compressive and lateral forces. Cells in this layer are characterized by the expression of Sox-9, Collagen types I and II, and Indian hedgehog. ${ }^{17}$

The fourth and deepest zone is the hypertrophic zone. In this zone, the chondrocytes become hypertrophic, die, and have their cytoplasm evacuated, forming bone from within the medullary cavity. Cartilage breakdown occurs, and cartilaginous spicules undergo calcification with hydroxyapatite crystals. The surface of the extracellular matrix scaffolding provides an active site for remodeling activity as endosteal bone growth proceeds. Deeper into the zone, bone and marrow spaces are present. The bony trabeculae are arranged randomly and not perpendicular to the articulating surface. Cells in this zone are characterized by the expression of Indian hedgehog, Osteopontin, and Collagen type X. ${ }^{17}$

The TMJ disc is an articular disc composed of dense fibrous connective tissue, which is primarily deficient of any blood vessels or nerve fibers. The disc lies in between the condyle of the mandible and the mandibular fossa of the temporal bone. The disc divides the joint cavity into two distinct components: the upper compartment and the lower compartment. The upper or superior cavity is delineated by the mandibular fossa and the superior surface of the disc. The lower or inferior cavity is bordered by the mandibular condyle and inferior surface of the disc. Each compartment is filled with a plasma-like synovial fluid secreted by cells of the synovial lining. Synovial fluid serves as a multipurpose substance. Since the articular disc and the articular surfaces of the joint are devoid in vasculature, the synovial fluid acts as a vehicle for providing metabolic requirements for these tissues. Also, the synovial fluid aids in minimizing friction by serving as a lubricant in between all these articular surfaces. ${ }^{19}$

The morphology of the disc matches the shape of the condylar head and the mandibular fossa. In the frontal view, the disc is concave inferiorly, designed to fit over the condylar head, and concavely superiorly to fit the convex surface of the mandibular fossa of the temporal bone. ${ }^{20}$ The articular disc is attached firmly to the medial and lateral poles of the condyle in order to prevent the disc from excessively moving during condylar movements. In the sagittal plane, it can be divided into three regions according to thickness. The central area is the thinnest; the anterior and posterior regions are much thicker in comparison. From the anterior view, the disc is thicker medially than laterally. The articular disc is attached posteriorly to a region of loose connective tissue, known as the retrodiscal tissue, which is highly vascularized and innervated. ${ }^{19}$ Cells of the TMJ disc are characterized by the expression of Versican ${ }^{21}$ and little expression of Collagen type II..$^{22}$ Interestingly, the TMJ disc does not form in mice deficient for Indian hedgehog. ${ }^{17}$

\section{Uniqueness of the TMJ}

The TMJ is different in composition and development from other joints in the body. Therefore, it is not surprising that there are certain diseases that affect every joint in the body except for the TMJ. Conversely, it is likely that the unique age and gender distribution of TMJ disorders may result from these differences between the TMJ and systemic joints. In other synovial joints in the body, the articular surfaces are covered by hyaline cartilage. The TMJ is different because it is composed of fibrocartilage. ${ }^{23}$ One of the unique characteristics of fibrocartilage is that it contains both types I and II Collagens, compared to articular hyaline cartilage, which only contains type II Collagen. ${ }^{24}$ Fibrocartilage is better able to withstand sheer forces than hyaline cartilage can, which makes it a superior material for enduring the large amount of occlusal load that is placed on the TMJ. ${ }^{25}$ Other advantages of fibrocartilage in the TMJ over hyaline cartilage are that the fibers are tightly packed and are able to withstand the forces of movement; it is less susceptible to the effects of aging; it is less likely to break down over time; and it has a better ability to repair. ${ }^{26}$ On the other hand, fibrocartilage may be 
targeted differently from hyaline cartilage by factors such as sex hormones that predispose to degenerative changes as discussed below.

Another difference between the TMJ and other joints is that the cartilage of the mandible condyle is a secondary cartilage compared to the articular cartilage found in other joints, which is a primary cartilage. ${ }^{27}$ More specifically, secondary cartilage develops in association with specific bones formed by intra-membranous ossification after the bones are already formed. This is different from cartilage associated with endochondral ossification, where the cartilage precedes the bone formation and is referred to as a primary cartilage. Primary cartilage growth begins in the cartilage cells within the central layer of an epiphyseal plate. In this developmental stage, the cells undergo mitosis. The two daughter cells will contain the total amount of genetic information from the original cell. In the next phase of epiphyseal growth, the two daughter cells enlarge to the size of the original. Each cell produces and secretes extracellular matrix, which causes the cells to drift away from each other and to enter various pathways. The cells may either become a new progenitor cell or be replaced by bone. One of the key elements of primary cartilage growth is that growth occurs in the middle part of an epiphyseal plate of a long bone. When new growth occurs within existing tissue, it is called interstitial growth. ${ }^{28,29}$

Secondary condylar cartilage growth begins with undifferentiated cells comprising mesenchymal tissue covering the prenatal or postnatal condyle. In the developmental stages, the mesenchymal cells split within themselves to become even smaller cells, but eventually attain full size. These mesenchymal cells then migrate into the interior condyle, and from there into the cartilage, where differentiation occurs and the cells become immature cartilage cells. ${ }^{29}$ The growth in the cartilage has occurred through differentiation of mesenchymal tissue rather than mitosis of cartilage progenitor cells. Where growth occurs from the exterior, it is known as appositional growth. ${ }^{28}$

Two developmental defects, Hunter-Thompson chondrodysplasia and fibroblast growth factor-receptor 3 (FGF-R3) achondroplasia, both of which afflict systemic load-bearing joints but not the TMJ, provide further evidence for the uniqueness of the TMJ. Hunter-Thompson chondrodysplasia results from a twenty-two-base pair frameshift mutation of the $c d m p 1$ gene, and contributes to a complete loss of function of the growth factor cartilage-derived morphogenetic protein-1 (CDMP1), a member of the bone morphogenic protein superfamily. CDMP1 is located and expressed in the synovial-lined load-bearing joints during embryological development. This protein has high expression levels in the distal parts of limbs, suggesting an important role of CDMP1 in the development of the appendicular skeleton and joint morphogenesis. ${ }^{30}$ Individuals with HunterThompson chondrodysplasia have dysmorphic joints and are usually short in stature, but show no defects of the TMJ. ${ }^{30}$

FGF-R3 achondroplasia results from a defect in cell signaling, with a subsequent reduction of chondrocytes in the growth plate. Patients with this disorder have a point mutation in arginine or glycine in the gene that codes for FGF receptor 3. Under normal conditions, FGF-R3 activation inhibits cartilage proliferation; however, the mutation in this gene causes a gain of function of this FGF receptor, causing the receptor to be in constant activation. Phenotypically, the genetic disorder is expressed as shortened proximal extremities and an enlarged head with bulging forehead and depression of the root of the nose. ${ }^{31}$ Interestingly once again, although most other joints in the body are affected by this point mutation, the TMJ condylar cartilage does not seem to be affected. ${ }^{32}$

As outlined above, even though not fully characterized, the TMJ demonstrates specific organizational, anatomic, and developmental differences from other joints. Therefore, broad assumptions derived from knowledge about articular hyaline cartilage to explain or find appropriate treatments for TMJ disorders are not generally justified. The implications of these differences between the TMJ and systemic joints are likely to have implications for the causation, predisposition to, or progression of TMJ diseases and require further study.

\section{Pathogenesis of Degenerative TMJ Diseases}

Degenerative diseases of the TMJ occur from the loss in equilibrium of anabolic and catabolic processes involving chondrocyte initiation, proliferation, differentiation, and matrix synthesis and degradation. It is characterized by increased degradation of the components of the extracellular matrix and is usually preceded or accompanied by enhanced levels of inflammatory mediators. The initial signs of degenera- 
tive TMJ disease may be sub-clinical; consequently, onset of symptoms may not present until later stages of development of the disease. While the causes or contributing factors for degenerative TMJ disease remain largely speculative, three main etiologies have been proposed in the literature on the pathogenesis of these diseases: altered mechanical loading, female hormones, and alterations in the extracellular matrix. It is plausible that any one of these alone or in concert may predispose any given individual to degenerative changes in the joint. Findings from such studies are likely to help define novel diagnostic and treatment strategies.

\section{Trauma and/or Aberrant Mechanical Loading}

One of the possible etiologies of TMJ degenerative disease is aberrant mechanical loading by either trauma or altered masticatory function. Most dentists and physicians have been inclined to believe that the single most important etiological factor for degenerative TMJ disease is altered mechanical loading that surpasses the adaptive capacity of the joint. ${ }^{25,33}$ Studies in mice, rats, rabbits, and non-human primates have shown that normal masticatory function is important for maintaining normal growth, morphology, and function of the cartilage of the TMJ. In order to examine the effects of altered masticatory function on the TMJ in rodents, investigators have manipulated the masticatory sequence, which can be classified into two stages: incision and chewing. ${ }^{34}$

Trimming the incisors out of occlusion (believed to decrease the occlusal force during the incision stage and decrease the amount of protrusion that occurs during the incision stage ${ }^{35,36}$ ), replacing the standard hard pellet diet with a mushy soft diet (believed to decrease the amount of molar force required during the chewing stage ${ }^{35,36}$ ), or a combination of the two are all methods used to manipulate the masticatory sequence. Altering masticatory loading by the administration of soft diet and/or incisor clipping in rodents causes structural changes within the mandibular condylar cartilage and subchondral bone. In the mandibular condylar cartilage, altering the TMJ masticatory loading causes a decrease in the thickness of the mandibular condylar cartilage, ${ }^{37-39}$ a reduction in the expression of extracellular matrix proteins in the cartilage, ${ }^{40}$ and a reduction of chondrocyte proliferation. ${ }^{36,41,42}$ In the subchondral bone, we have recently found that incisor trimming and soft diet administration cause a transient decrease in the bone volume and trabecular thickness of the mandibular condylar subchondral bone for two to four weeks, which were restored to normal levels over four to six weeks (Wadhwa et al., submitted for publication). We believe that these changes in the subchondral bone by altered TMJ masticatory loading are consistent with changes in the subchondral bone reported for TMJ osteoarthritis.

Traumatic injuries are also an important etiological factor in the development of TMJ disorders. One study examining 400 consecutive TMD clinical patients found that, in 24.5 percent of patients, the onset of the pain could be linked directly to the trauma. ${ }^{43}$ Individuals who have been in automobile accidents and sustained whiplash injuries seem especially prone to develop TMDs. In recent studies, it has been shown that there is an increase in developing reduced or painful jaw movements immediately after whiplash injury ${ }^{44}$ and that one in three people who are exposed to whiplash trauma are at risk of developing delayed TMJ symptoms. ${ }^{45}$

\section{Hormonal Pathogenesis}

Because of the high prevalence of TMDs in women of reproductive age, ${ }^{27}$ it has been postulated that sex-based determinants, such as hormonal influences from estrogen, progesterone, and relaxin, may make an individual susceptible to degenerative TMJ diseases. Several lines of evidence support this hypothesis. Both estrogen and progesterone receptors have been localized in the TMJ of human and non-human primates, ${ }^{46-48}$ in male rats, ${ }^{49}$ and in mice of both genders, ${ }^{50}$ with some findings suggesting a sexual dimorphism in the presence of estrogen receptors. ${ }^{47}$ Other evidence that estrogen is involved in TMDs includes an association between facial pain and estrogen replacement therapy or the use of oral contraceptives $^{51,52}$ and elevated systemic levels of estrogen in women with TMJ disease versus those in normal controls.$^{53}$ In addition, polymorphisms in the estrogen receptor have been shown to be correlated to the intensity of pain, ${ }^{54}$ facial axis angle, ${ }^{55}$ and mandibular body length ${ }^{55}$ in patients who suffer from TMJ osteoarthritis. However, despite these studies, until recently no direct evidence has been found that links female reproductive hormones to TMJ disease or that defines the mechanisms by which these hormones may cause TMJ disease.

Recent findings by our group demonstrate that estrogen and relaxin may contribute to TMJ degeneration by enhancing the expression of tissue-degrading 
enzymes belonging to the matrix metalloproteinase (MMP) family from TMJ fibrocartilage. MMPs can degrade the major matrix macromolecules of cartilage (namely, collagen and proteoglycans), as well as most of the minor proteins in this tissue. Our studies show that relaxin and/or estrogen induce specific MMPs - namely, MMP-1 (collagenase-1), MMP-3 (stromelysin-1), MMP-9 (92 kDa gelatinase), and MMP-13 (collagenase-3) - in mice and/or rabbit TMJ disc fibrochondrocytes, ${ }^{56-58}$ suggesting a plausible role of these enzymes in hormone-mediated joint degeneration. Interestingly, the key matrix substrates for MMP-1 and MMP-13 are fibrilar collagens, including types I and II collagens, and those for MMP-3 and MMP-9 are proteoglycans, ${ }^{59,60}$ which together comprise the largest proportion of the matrix molecules of fibrocartilage. Indeed, we have shown that the modulation of MMPs by relaxin and estrogen are paralleled by changes in the predominant matrix molecules collagens and proteoglycans in TMJ disc fibrocartilage in vitro and in vivo ${ }^{57,61}$ (Figure 2), suggesting a potential relationship between hormone-modulated MMPs and extracellular matrix homeostasis or degradation. Because matrix degradation by MMPs is considered to be a primary event in the initiation and progression of joint disease, this hormone-mediated loss in matrices likely affects the ability of the joint to sustain normal function and can lead to progressive degenerative changes in the joint. These findings, together with the elevated levels of estrogen in women with TMJ disease, ${ }^{52}$ suggest a potential role of specific sex hormones in causing or predisposing to TMJ degeneration.

\section{Genetic Basis for Altered Joint Extracellular Matrix}

Another possible mechanism by which degenerative diseases of the TMJ may arise is from alterations in the extracellular matrix, caused directly from genetic perturbations or indirectly from factors or hormones (as described above) that influence the composition and/or turnover of the extracellular matrix of the TMJ. Alterations in the extracellular matrix as a possible mechanism behind degenerative TMJ diseases are supported by studies in transgenic mice that have defects in the extracellular matrix and develop TMJ osteoarthritis. To date, three mouse models with defects in the extracellular matrix of the mandibular condylar cartilage have been shown to develop TMJ osteoarthritis. ${ }^{62-64}$ In one of these models, termed Del1, the transgenic mice produce a
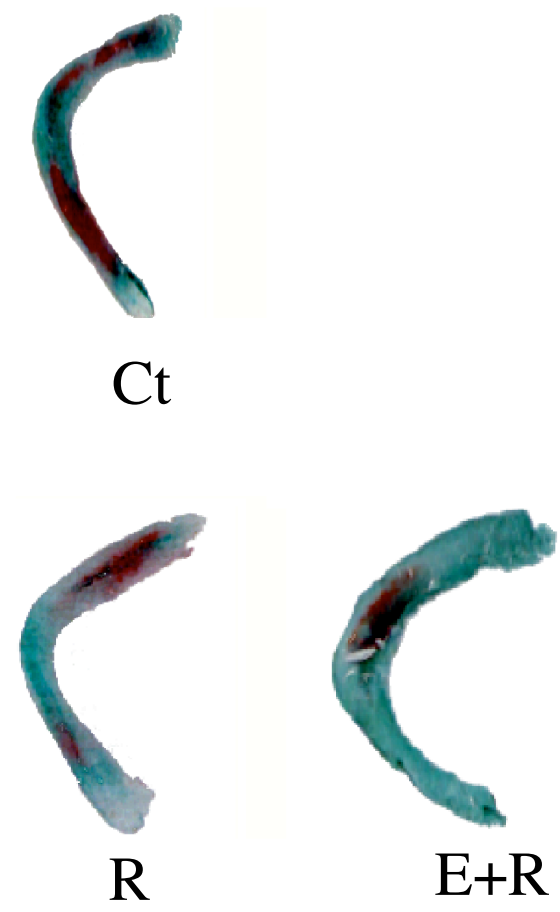

Figure 2. Relaxin with or without estrogen decreases the proteoglycan content of TMJ disc fibrocartilage

TMJ discs cultured in control medium $(\mathrm{Ct})$ or in the presence of relaxin $(R)$ or estrogen plus relaxin $(E+R)$ were stained for proteoglycans (stained red), a major matrix molecule in the disc. Discs cultured with relaxin or estrogen plus relaxin showed approximately 50 percent reduction in proteoglycan content.

Data from: Naqvi T, Duong TT, Hashem G, Shiga M, Zhang Q, Kapila S. Relaxin's induction of metalloproteinases is associated with the loss of collagen and glycosaminoglycans in synovial joint fibrocartilaginous explants. Arthritis Res Ther 2005;7:R1-11.

mutated form of the human type II collagen (Col2A1) gene driven by the human collagen type II promoter, resulting in the mutant protein being expressed solely in cartilage. ${ }^{62}$ Mice with this mutation develop subchondral cysts in the mandibular condyle and clefting at three months, and by fifteen months the mandibular condylar cartilage was almost completely resorbed. The authors hypothesize that the osteoarthritic lesions are due to a decreased repair response and by changes in the tissue's micro-architecture, which cause them not to be able to withstand the strain and loading as well as wild-type controls. 
The second mouse model of TMJ osteoarthritis has a loss of function mutation in the gene encoding the alpha-1 chain of type XI collagen of cho (chondrodysplasia) mice. ${ }^{65}$ At three months, heterozygote cho mice show evidence of osteoarthritic changes in proteoglycan staining in the superficial articular layer of the mandibular condylar cartilage. By nine months of age, fibrillations extend across the entire surface of the mandibular articular cartilage. The observations suggest that the loss of proteoglycan in the TMJ cartilage of the cho-deficient mice leads to increased exposure of the chondrocytes with type II collagen fibrils. The chondrocyte-type II collagen fibril interaction in the TMJ leads to signaling through the discoidin domain receptor, DDR2, which induces the activity and expression of MMP-13 contributing to extracellular matrix cartilage degradation. ${ }^{63}$

The third TMJ-osteoarthritis mouse model involves deficiencies in the production of two extracellular matrix proteoglycans: biglycan and fibromodulin. At six months of age, osteoarthritic changes first begin to develop in the TMJ and progressively get worse, and by eighteen months, the double-deficient mice have almost complete destruction of the TMJ (Figure 3). Biglycan is a small proteoglycan abundant in cartilage, bone, and other connective tissues
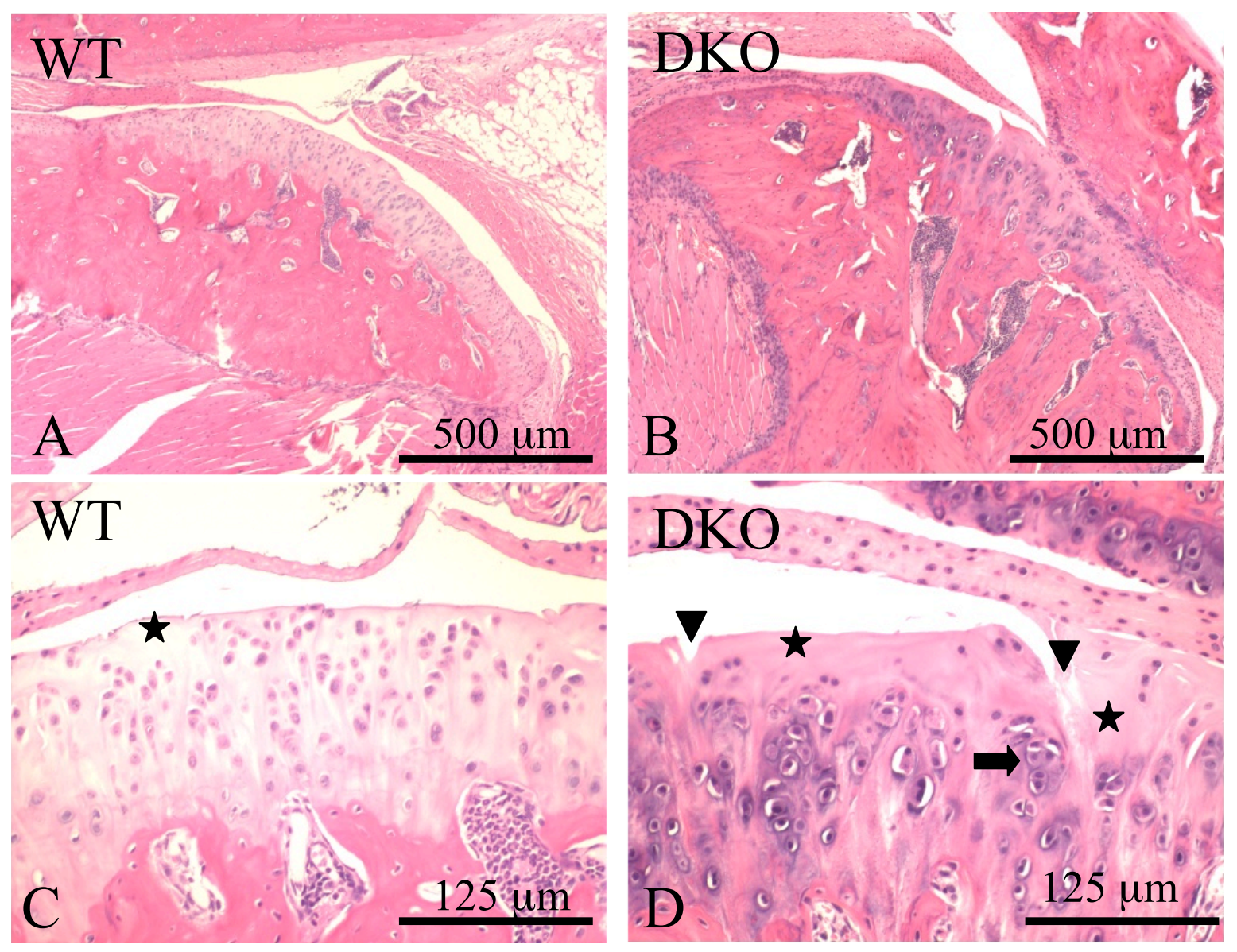

Figure 3. Sections of the TMJ from nine-month-old wild type (WT) (A and C) and biglycan/fibromodulin double knockout (DKO) mice (B and D) stained with hematoxylin and eosin

The arrowheads show vertical clefts, the asterisks show the small acellular areas under the articular surfaces, and the arrow shows regions where chondrocytes lose their regular columnar organization and form clusters.

Reprinted with permission from Wadhwa S, Embree MC, Kilts T, Young MF, Ameye LG. Accelerated osteoarthritis in the temporomandibular joint of biglycan/fibromodulin double-deficient mice. Osteoarthritis Cartilage 2005;13:817-27. 
whose function is not yet understood. Fibromodulin is a collagen-binding protein that is homologous to biglycan structurally, lending support to the idea that both proteoglycans arose from the same ancestral gene. Fibromodulin was isolated from cartilage and is present in many types of connective tissue, including cartilage, tendon, skin, sclera, and the cornea. These proteoglycans have several properties that are important in the resiliency of articular cartilage. They aid in providing water for surface lubrication, are associated with collagen, and may aid in directing the formation and spatial orientation of the collagen fibrils.

Although the exact mechanism of TMJ osteoarthritis is unknown, the absence of biglycan/ fibromodulin may cause changes in the extracellular collagen network, making the joint less susceptible to withstanding mechanical loading and subsequently more prone to osteoarthritic lesions. ${ }^{64}$ In support of this notion, it has been observed that, in the knee of double-knockout biglycan/fibromodulin mice, increased mechanical loading by forced treadmill running caused an increased severity of osteoarthritis in the knee. ${ }^{66}$ Another explanation is that changes in the TMJ fibrocartilage arise from the ability of biglycan/fibromodulin to modulate members of the transforming growth factor (TGF)- $\beta$ superfamily. The binding of biglycan and fibromodulin to members of the TGF- $\beta$ family may regulate their activity by sequestering them into the extracellular matrix, thereby preventing their binding with the cellular receptors. Evidence has been shown by examination of another small leucine-repeat, proteoglycan-deficient mouse in which bone marrow stromal cells from biglycan/ decorin double-deficient mice showed an increase in TGF- $\beta$ activity. ${ }^{67}$

Although these animal models point towards the intriguing possibility for a genetic basis of degenerative TMJ diseases, there is currently no evidence for these factors in the human disease. However, it is possible that future studies will uncover such links between genetic defects in the extracellular matrix and TMJ disorders, which may provide a basis for identifying individuals who have a predisposition to the diseases.

\section{Rational Diagnostics and Therapeutics}

The recent progress in understanding the biomedical basis for TMJ disorders discussed above, as well as in computer and imaging technologies, is beginning to provide novel insights into the pathogenesis of degenerative TMJ diseases and point towards the possible use of this knowledge in devising rational diagnostic and therapeutic strategies. Some of the likely uses of these approaches in diagnosis, prognostics, and therapeutics are outlined below.

\section{Imaging}

Several methods are available for imaging the TMJ. These include basic radiography (such as panorexes and corrected tomograms), ultrasonography, magnetic resonance imaging, and spiral or conebeam computed tomography. The latter technologies allow the joint to be visualized as sections in different planes and can also be rendered as 3D volumetric reconstructions to enhance diagnostic capabilities (Figure 4). Magnetic resonance imaging and ultrasonography have the added advantage over CT scans in that they enable soft tissues such as the disc, ligaments, and muscles to be visualized and may be more useful than CTs when the patient presents with internal derangement or joint dysfunction. ${ }^{68,69}$ With currently available software, which is relatively user-friendly, the raw DICOM files obtained from MRI or CT scans can be compiled, manipulated, and visualized by the clinician in the office.

The introduction of the conebeam CT (CBCT) systems specifically designed for use in dentistry has opened up new opportunities for deriving additional diagnostic information (Figure 4). Although CT scans and MRI have been available for many years, several barriers have precluded their widespread use in evaluating TMJ disorders. These include high cost, radiation exposure (in the case of CT scans), and, to a lesser extent, difficulty accessing units, most of which are located in hospitals and medical imaging laboratories. The introduction of $\mathrm{CBCT}$ units that are now available in dental schools, dental X-ray laboratories, and even private practices has eliminated some of these barriers to the use of advanced imaging technology, when indicated in specific cases.

One key issue in CBCT imaging involves its reliability and diagnostic capabilities relative to the spiral CT and conventional tomography. This question has been assessed by several investigators. ${ }^{70-72}$ In studies comparing spiral CT and CBCT, no significant differences were observed in findings of osseous abnormalities. ${ }^{72}$ The specificity of the condyle assessment was 1.0 with both CBCT and spiral CT, and the sensitivity was 0.8 and 0.7 for these two imaging modalities, respectively. The investigators concluded that $3 \mathrm{D}$ images rendered by $\mathrm{CBCT}$ are a dose-effec- 

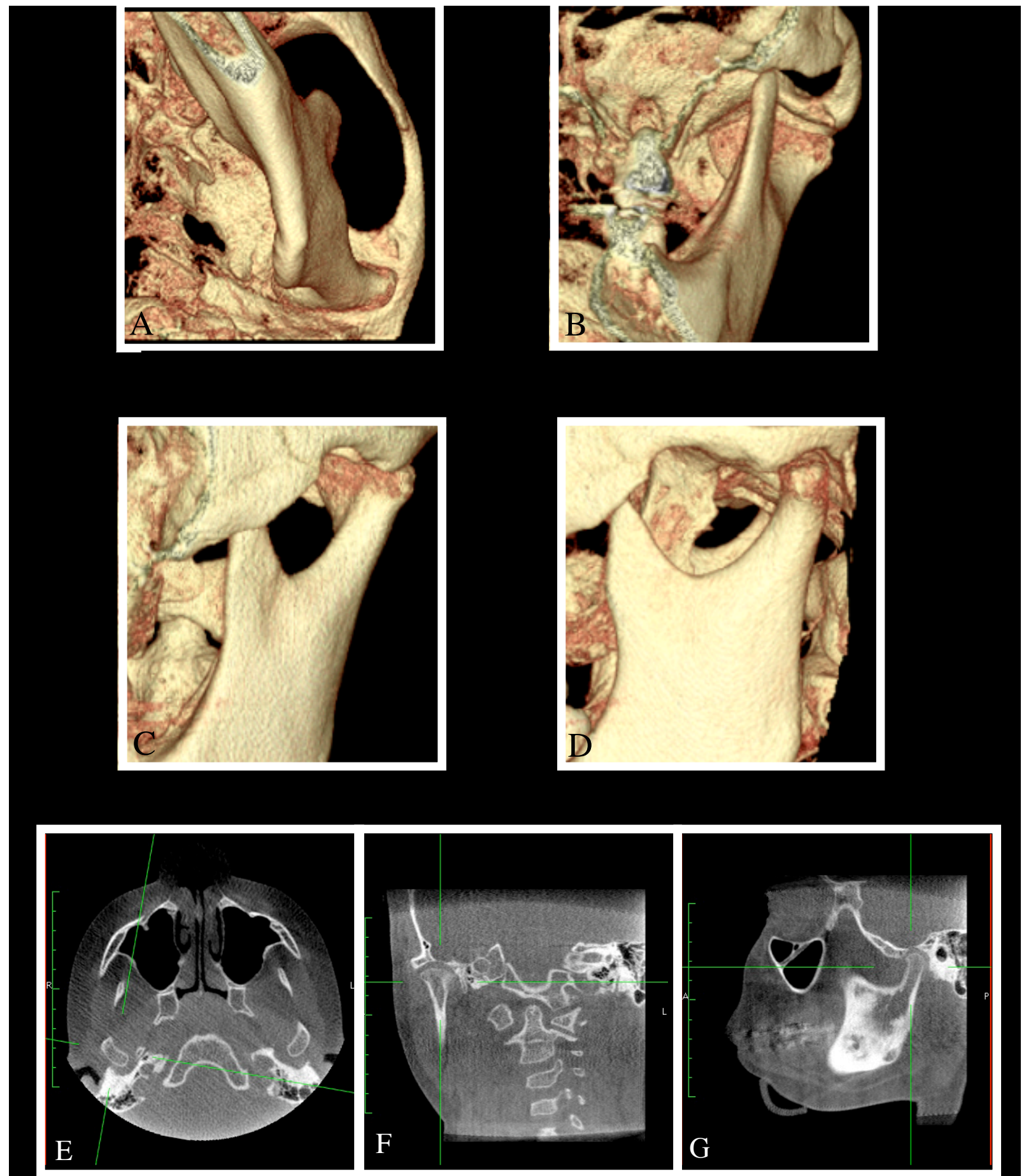

Figure 4. New opportunities for additional diagnostic information available with conebeam CT systems

Conebeam computed tomographic images can be manipulated to derive three-dimensional volumetric images that can be viewed from any perspective with superimposing tissues dissected out to clearly visualize the region of interest (A to D) or sections of desired thicknesses derived in any plane of interest-in this case, axial (E), coronal (F), and sagittal (G) views of the TMJ. 
tive and cost-effective alternative to spiral CT for the diagnostic evaluation of osseous mandibular condyle abnormalities. Additional studies on the accuracy of linear measurements in CBCT-derived, multiplanarreformatted projections for the TMJ compared to anatomical measures of skulls and in cephalograms showed high accuracy of these measurements on the CBCT, but not on the lateral or PA cephalograms. ${ }^{73}$ Additionally, the intraobserver measurements on the CBCT reconstructions were highly reliable relative to the anatomic truth, and significantly more so than those from the cephalograms. These findings together provide support for the utility of CBCT imaging for both diagnostic and research purposes in TMJ disorders.

The possible use of CBCT imaging technology has been tested for various applications in TMJ disorders. This includes its use in image-guided access to the superior joint space for arthroscopic examination and treatment of individuals with disc perforations or adhesions. ${ }^{74}$ This technique may improve the safety of arthroscopic procedures by decreasing the probability of inadvertent puncturing of the glenoid fossa into the middle cranial fossa. Future modifications to $3 \mathrm{D}$-imaging methodologies are likely to involve techniques that enhance the sensitivity and specificity of these techniques. In one such approach, we determined whether the histopathologic severity of TMJ inflammation in an animal model of arthritis correlated with quantitative changes over time in the MRI signal from a macromolecular contrast agent, GdDTPA $_{30}{ }^{75}$ The arthritic TMJs showed marked enhancement of the synovial and subsynovial tissues, which had strong positive relationships with all histologic parameters of arthritis, indicating its utility for assessing the severity of joint inflammation (Figure 5). This or similar techniques may be useful for increased sensitivity and specificity of diagnosis, and as an aid in the noninvasive monitoring of disease severity and treatment response in arthritis. Finally, as discussed below, 3D images derived from these technologies are likely to become an important and integral part of bioengineering custom TMJs for subjects in irreversible stages of joint disease.

\section{Biomedical Approaches to Diagnose, Alleviate, or Prevent Joint Degeneration}

Systemic and Local Biomarkers of Disease. Biomarkers of diseases are a highly sought after approach for the early diagnosis of various condi- tions and for evaluating the efficacy of treatment modalities. Various sources of samples are used for the assaying of disease biomarkers. In the case of joint disorders, these samples have included synovial lavages or aspirates, tissue samples, serum or plasma, or urine. The most common sample used in studies performed to date is synovial lavages to determine the changes in various local biological mediators of disease that may be used subsequently in predicting the status of the disease. Findings from such studies have demonstrated increased levels of inflammatory mediators, ${ }^{76-78}$ MMPs, ${ }^{77,79-82}$ and aggrecanase ${ }^{80,83}$ in patients with TMJ disorders versus controls. While the synovial lavage or aspirate samples are typically obtainable from subjects undergoing arthrocentesis, their availability for routine diagnostics is questionable because of the invasive nature of the procedure. Also, inherent limitations in the methodology, including unknown dilution effects, make it difficult to compare data between subjects and over time ${ }^{84}$ and diminish the utility of this approach for diagnostic purposes.

Synovial tissues from patients with TMJ disorders are also a source for evaluating potential biomarkers. Investigators using these samples have shown that there is increased expression of $\mathrm{Il}-8^{85}$ and microvessel density ${ }^{86}$ in TMD patients. However, similar to synovial fluid, the invasiveness of the procedure to obtain samples makes the evaluation of synovial tissues less than ideal. A less invasive sampling involves assays on urine or serum. Assays on urine samples have shown elevated levels of pyridinoline (Pyr) and deoxypyridinoline (Dpyr) collagen cross-links, which are known markers of bone and cartilage turnover, in patients with osteoarthritis of the TMJ. ${ }^{87}$ Additionally, elevated amino acid secretion products were found in the urine of patients with chronic muscle pain TMD. ${ }^{88}$ Similarly, preliminary studies using serum have suggested increased estrogen levels ${ }^{53,89}$ in TMD patients and increased levels of interleukin-1 beta and C-reactive protein in arthritic TMJ diseases. ${ }^{90}$ No studies have been done to assay for potential biomarkers of TMJ disorders using saliva, which would be a highly desirable source for assaying biomarkers for disease or therapeutic outcomes. Also, while the studies cited above provide insights into potential biomarkers of TMJ diseases, much work remains to be done to demonstrate the specificity and sensitivity of any given marker of the disease status.

While a "gold standard" biomarker for TMJ disorders remains elusive, powerful new technologies 

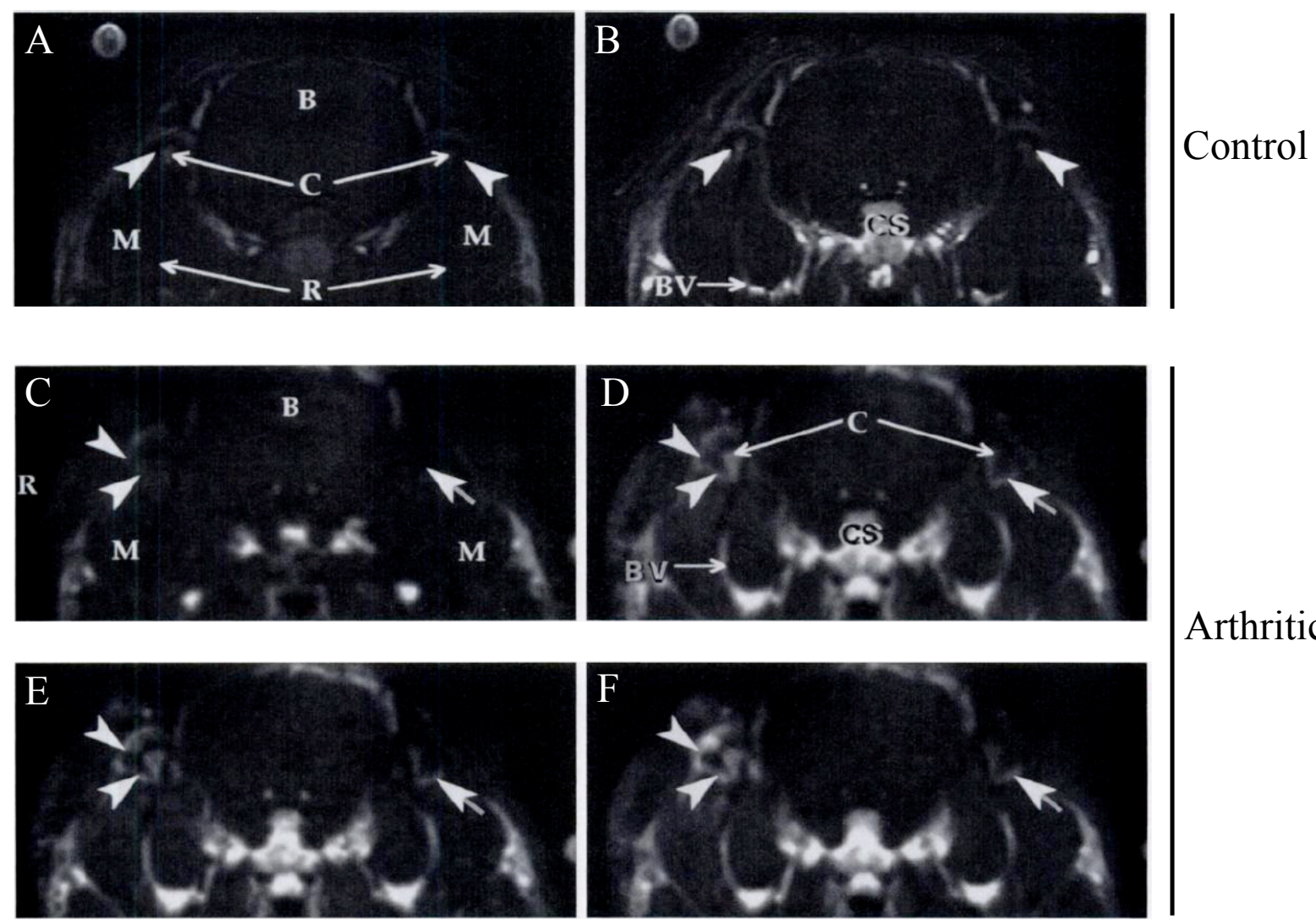

Arthritic

Figure 5. A macromolecular contrast agent, albumin-(Gd-DTPA)30 in conjunction with dynamic MRIs provides quantitative and sensitive data on the magnitude of vascular permeability and extravasation that correlates very highly with the severity of joint inflammation

The upper panel demonstrates precontrast $(\mathrm{A})$ and 30-minute postcontrast (B) coronal section of MR images from a control rabbit with no joint inflammation. The postcontrast image shows the expected enhancement of blood vessels (BV), the cavernous sinus (CS), and other vascular structures, but only minimal enhancement in the synovium of the TMJs (arrowheads). On the other hand, rabbits with TMJ inflammation showed a gradual increase in enhancement of the inflamed synovium from the precontrast time point (C) to 2 (D), $10(\mathrm{E})$, and $30(\mathrm{~F})$ minutes after intravenous administration of the contrast agent (depicted by arrows and arrowheads). The histologic total arthritic score was highly correlated to the rate of tissue enhancement. $R=$ rami of mandible; $\mathrm{B}=$ brain; $\mathrm{C}=$ condylar heads; $\mathrm{M}=$ masseter muscle; $\mathrm{R}=$ right.

Reprinted with permission from van Dijke CF, Kirk BA, Peterfy CG, Genant HK, Brasch RC, Kapila S. Arthritic temporomandibular joint: correlation of macromolecular contrast-enhanced MR imaging parameters and histopathologic findings. Radiology 1997;204:825-32.

such as microarrays on tissue, synovial fluid, or serum samples may enable the identification of specific and sensitive biomarkers of TMJ disease in the future. Microarrays permit the analysis of the expression of thousands of genes even with extremely small quantities of sample. Therefore, the use of microarrays on blood samples from patients with TMJ disorders may be able to identify novel genes or combination of genes that are predictive of TMDs. In a recent study, ${ }^{11}$ microarray analysis of 3,543 genes in blood samples in patients with mild knee osteoarthritis and non-symptomatic controls revealed nine genes considered to be predictive of knee osteoarthritis. These nine genes were then used to blindly evaluate a new sample of sixty-seven subjects and demonstrated 72 percent sensitivity and 66 percent specificity as a test for osteoarthritis. In the next few years, it is likely that tests based on findings from such studies will become commercially available as viable tools to aid the clinician in the early and specific diagnosis 
of various joint disorders, including those involving the TMJ. Studies such as these are also likely to help identify key pathways and bioactive molecules that contribute to the perpetuation of the disease that can be targeted for rational therapeutics.

Genotyping to Identify Subjects at Risk. Genetic factors may play a role in determining which individuals are more prone to develop TMJ disorders or in predicting the severity of the disease process. Although recent evidence points to the contrary, TMJ disorders traditionally have been believed to have no heritability. The support for TMJ diseases not having a genetic component is provided by studies showing that the incidence and severity of these disorders were not different in monozygotic twins compared to dizygotic twins.$^{92}$ If TMJ disorders had a heritable component, one would expect an increase in the incidence of the disease in monozygotic twins that are genetically identical compared to dizygotic twins that are not genetically identical. In contrast, recent studies have shown that polymorphisms in the serotonin transporter gene $\mathrm{e}^{93}$ and adrenergic receptor beta gene $2^{94}$ cause an increase in the likelihood of developing TMJ disorders. Also, polymorphism in the estrogen receptor gene causes an increase in pain susceptibility in patients with TMJ osteoarthritis. ${ }^{54}$ The differences in findings between studies on the heritability of TMJ disorders may have resulted from the inclusion of the many different subtypes of the diseases with some having a greater genetic component while others have minimal or no genetic basis.

Recently, significant resources have been directed towards high-throughput genome sequencing, and it seems highly likely that in the next ten to twenty years health professionals will have their patients' genomes available for analysis. This diagnostic tool, coupled with advances in understanding the genes that contribute or predispose to TMJ disorders, may make it possible to identify patients who are at risk for developing TMJ disorders and enable the implementation of strategies to prevent the disease.

\section{Using Technology and Biomedicine to Engineer the TMJ}

For many people suffering from severe and painful degenerative diseases of the TMJ, surgical replacement of the mandibular condyle remains the only option. Until recently, the primary methods employed to reconstruct the TMJ included autogenous tissue grafting, for example from the rib, or the use of alloplastic materials, with neither being ideally suited for the task and sometimes leading to extremely deleterious effects. ${ }^{95,96}$ Fortunately, due to recent advances in the understanding of stem cell biology and biomaterials, it seems that in the near future it may be possible to successfully reconstruct a bioengineered TMJ replacement that is compatible with a host, biologically viable, and capable of withstanding the physiologic loads required of this joint.

Tissue engineering involves developing in vitro and/or in vivo a biological replacement that mimics the biological, morphological, and organizational characteristics of the tissue it is replacing. The most common method for deriving engineered tissues involves the implantation of cells, typically derived from the host, into a biomimetic scaffold and then stimulating it in a bioreactor or in vivo with appropriate signals to derive a replacement tissue or organ..$^{97,98}$ Cells from various sources, including articular cartilage cells, fibroblasts, human umbilical cord matrix stem cells, and mesenchymal stem cells, have been used in efforts to reconstruct the TMJ. ${ }^{99,100}$ Of these cells, stem cells have gained increasing prominence in the tissue engineering of joints and have been used by various investigators for developing prototype TMJ condyles. Unlike primary cells such as chondrocytes that have limited capacity to propagate, stem cells have the additional advantage of being stimulated by specific biological cues into differentiating into osteoblasts, chondrocytes, fibroblasts, and myocytes (Figure 6). These cell types, in turn, generate cartilage, bone, ligaments, and muscles, respectively, to derive all key components of the TMJ complex. Thus, for example, in recent studies ${ }^{101,102}$ rat bone marrow mesenchymal stem cells were grown separately in chondrogenic differentiation media or in osteoblastic differentiation media. Subsequent transfer of the two cell populations into a scaffold with two stratified and integrated layers, and then implantation into the backs of immunodeficient mice for twelve weeks, resulted in a structure containing both cartilage and bone tissue in a construct of the shape and dimensions of human mandibular condyle.

Regardless of the source, cells require appropriate stimuli and materials or scaffold into which to be seeded in order to differentiate and express bone and cartilage matrices into suitable structural organization and anatomy of the TMJ. For this purpose, 3D imaging technologies can be used to design the scaffold of the same shape and size required at the defect site. Indeed, this use of image-based design coupled with solid free-form fabrication has been used to generate biomimetic scaffolds that are both load-bearing 


\section{Mesengenic process}

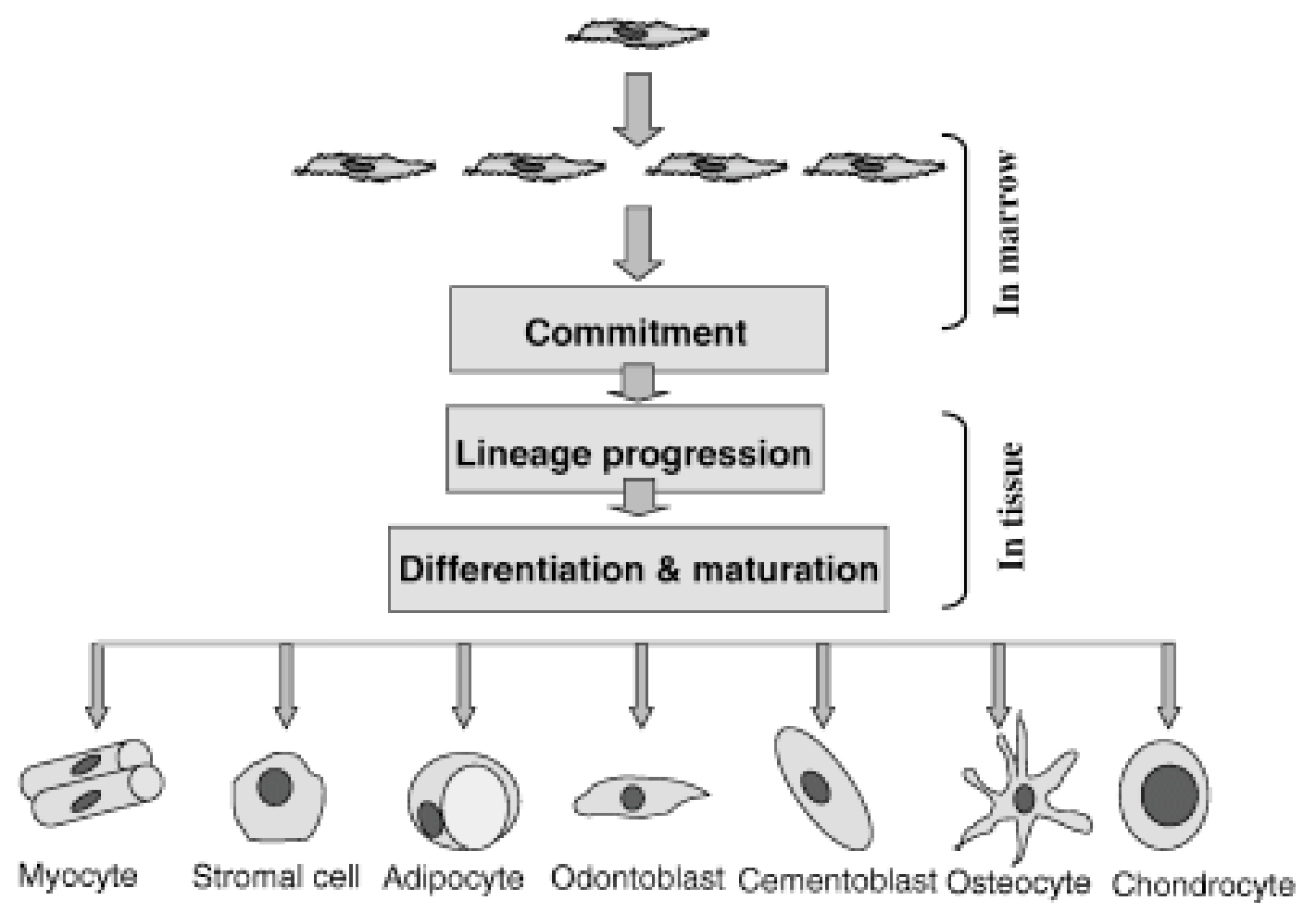

Figure 6. Mesenchymal stem cells can be stimulated to undergo differentiation into different cell lineages, including muscle, bone, cartilage, and ligament, which can be used to derive the entire TMJ complex

Commitment to a particular lineage is driven by the presence of local morphogenic factors. Lineage-committed cells progress through a number of transitory stages. Once differentiation is initiated, proliferation is down regulated, and tissue-specific proteins are expressed to generate the specific tissue. It is thought that mesenchymal stem cells are present in all organs of the body, where they serve to maintain tissue homeostasis.

Reprinted with permission from Risbud MV, Shapiro IM. Stem cells in craniofacial and dental tissue engineering. Orthod Craniofac Res 2005;8:54-9.

and match the defect site geometry ${ }^{100,103}$ (Figure 7). Further improvements in this approach have been used to generate Poly-l-lactic acid/hydroxyapatite composite biphasic composite scaffolds that, when seeded with chondrocytes as well as appropriately stimulated fibroblasts, respectively, resulted in the expression of cartilage and bone in discrete regions with a stable interface between cartilage and subchondral bone (Figure 8). Such approaches to TMJ tissue engineering provide site-specific anatomical configuration as well as autologous tissues that have the potential ability to adapt to the loading forces placed on it during function, and hold great promise for patients needing joint replacements.

\section{Conclusions}

As with other areas of medicine and dentistry, advances in biomedicine and computer-based technologies offer great promise for helping patients predisposed to or suffering from TMJ diseases. These technologies will enhance diagnostic capabilities and rational therapeutics or preventive strategies. 

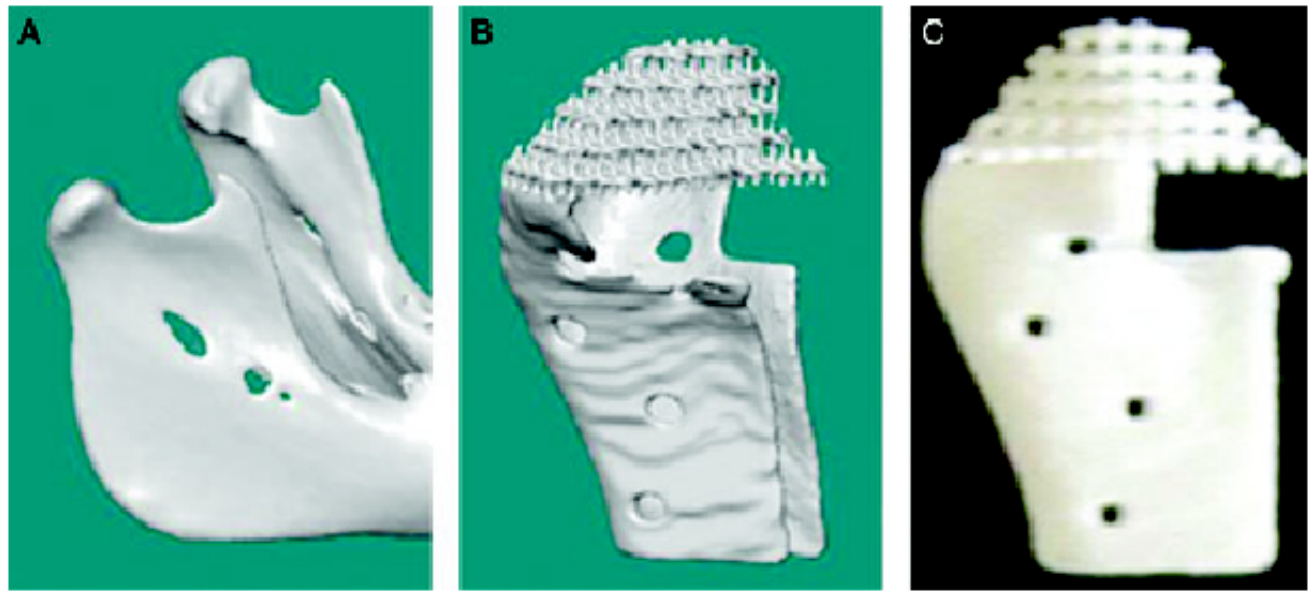

Figure 7. Image-based design enables the construction of scaffolds that are defect site-specific

The image of the patient or animal condyle $(\mathrm{A})$ is used to generate a computer microarchitecture structure of the desired implant design (B), which is used in turn to construct a solid free-form fabrication of the desired material or materials (C). Subsequently, the scaffold is seeded with cells and stimulated appropriately to generate bone and cartilage.

Reprinted with permission from Schek RM, Taboas JM, Hollister SJ, Krebsbach PH. Tissue engineering osteochondral implants for temporomandibular joint repair. Orthod Craniofac Res 2005;8:313-9.
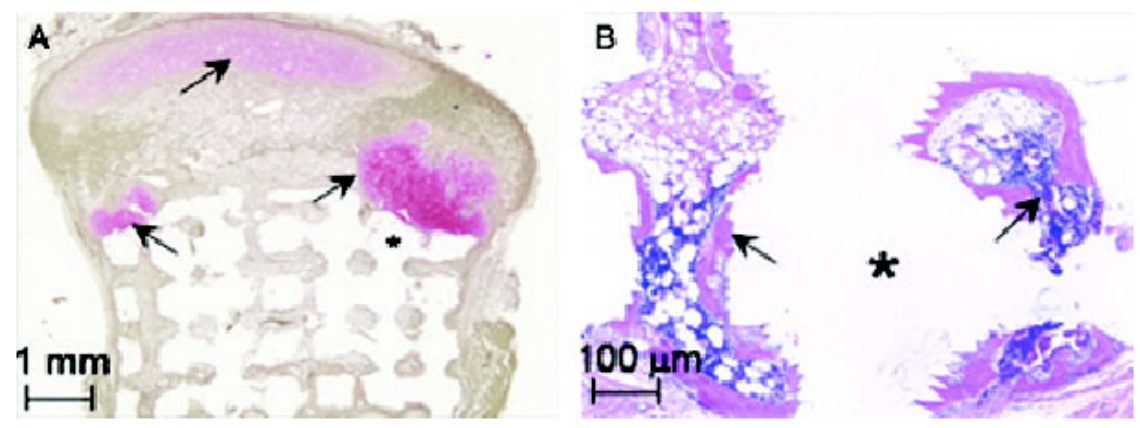

Figure 8. Composite scaffolds, shaped as the TMJ condyle, seeded with cells, and appropriately stimulated, generate osteochondral tissues mimicking the shape of the condyle

(A) Safranin-O and fast green staining shows pink-stained cartilage (arrows) in the condylar head in contact with the greenbrown stained bone. (B) Hematoxylin and esoin staining of the hyaluronic acid portion of the scaffold shows the formation of bone (arrows) with marrow space.

Reprinted with permission from Schek RM, Taboas JM, Hollister SJ, Krebsbach PH. Tissue engineering osteochondral implants for temporomandibular joint repair. Orthod Craniofac Res 2005;8:313-9. 
Genetic analysis, biomarkers, imaging, and tissue engineering will likely expand the repertoire and improve the specificity of diagnostic and therapeutic approaches for diseases of the TMJ. Progress in biomedicine, imaging, and computer technology also point to the need for academicians, researchers, and the health care community to appropriately educate and prepare future clinicians to take advantage of these innovations.

\section{REFERENCES}

1. LeResche L. Epidemiology of temporomandibular disorders: implications for the investigation of etiologic factors. Crit Rev Oral Biol Med 1997;8:291-305.

2. Gelb H, Bernstein IM. Comparison of three different populations with temporomandibular joint pain-dysfunction syndrome. Dent Clin North Am 1983;27:495-503.

3. Rieder CE, Martinoff JT. The prevalence of mandibular dysfunction. Part II: A multiphasic dysfunction profile. J Prosthet Dent 1983;50:237-44.

4. Rieder CE, Martinoff JT, Wilcox SA. The prevalence of mandibular dysfunction. Part I: sex and age distribution of related signs and symptoms. J Prosthet Dent 1983;50:81-8.

5. Dworkin SF, LeResche L. Research diagnostic criteria for temporomandibular disorders: review, criteria, examinations and specifications, critique. J Craniomandibular Disorders 1992;6:301-55.

6. Dworkin SF, LeResche L, DeRouen T, Von Korff M. Assessing clinical signs of temporomandibular disorders: reliability of clinical examiners. J Prosthet Dent 1990;63:574-9.

7. Lipton JA, Ship JA, Larach-Robinson D. Estimated prevalence and distribution of reported orofacial pain in the United States. J Am Dent Assoc 1993;124:115-21.

8. Von Korff M, Dworkin SF, Le Resche L, Kruger A. An epidemiologic comparison of pain complaints. Pain 1988;32:173-83.

9. Solberg WK. Epidemiology, incidence, and prevalence of temporomandibular disorders: a review. Presented at the President's Conference on the Examination, Diagnosis, and Management of Temporomandibular Disorders, Chicago, 1982.

10. Felson DT, Nevitt MC. The effects of estrogen on osteoarthritis. Curr Opin Rheumatol 1998;10:269-72.

11. Warren MP, Fried JL. Temporomandibular disorders and hormones in women. Cells Tissues Organs 2001;169: 187-92.

12. Carlsson GE, LeResche L. Epidemiology of temporomandibular disorders. Seattle: IASP Press, 1995.

13. Plesh O, Sinisi SE, Crawford PB, Gansky SA. Diagnoses based on the research diagnostic criteria for temporomandibular disorders in a biracial population of young women. J Orofac Pain 2005; 19:65-75.

14. Manfredini D, Chiappe G, Bosco M. Research diagnostic criteria for temporomandibular disorders (RDC/TMD) axis I diagnoses in an Italian patient population. J Oral Rehabil 2006;33:551-8.
15. Ohno S, Schmid T, Tanne Y, Kamiya T, Honda K, OhnoNakahara M, et al. Expression of superficial zone protein in mandibular condyle cartilage. Osteoarthritis Cartilage 2006; 14:807-13.

16. Jay GD, Torres JR, Warman ML, Laderer MC, Breuer KS. The role of lubricin in the mechanical behavior of synovial fluid. Proc Natl Acad Sci U S A 2007;104:6194-9.

17. Shibukawa Y, Young B, Wu C, Yamada S, Long F, Pacifici $\mathrm{M}$, et al. Temporomandibular joint formation and condyle growth require Indian hedgehog signaling. Dev Dyn 2007;236:426-34.

18. Suda N, Shibata S, Yamazaki K, Kuroda T, Senior PV, Beck $\mathrm{F}$, et al. Parathyroid hormone-related protein regulates proliferation of condylar hypertrophic chondrocytes. J Bone Miner Res 1999;14:1838-47.

19. Okesson J. Management of temporomandibular disorders and occlusion. $4^{\text {th }}$ ed. St. Louis: Mosby, 1998.

20. Laskin GC, Hylander W. TMD's: an evidence-based approach to diagnosis and treatment. Chicago: Quintessence, 2006.

21. Toriya N, Takuma T, Arakawa T, Abiko Y, Sasano Y, Takahashi I, et al. Expression and localization of versican during postnatal development of rat temporomandibular joint disc. Histochem Cell Biol 2006;125:205-14.

22. Detamore MS, Orfanos JG, Almarza AJ, French MM, Wong ME, Athanasiou KA. Quantitative analysis and comparative regional investigation of the extracellular matrix of the porcine temporomandibular joint disc. Matrix Biol 2005;24:45-57.

23. Benjamin M, Ralphs JR. Biology of fibrocartilage cells. Int Rev Cytol 2004;233:1-45.

24. Mizoguchi I, Nakamura M, Takahashi I, Kagayama M, Mitani H. A comparison of the immunohistochemical localization of type I and type II collagens in craniofacial cartilages of the rat. Acta Anat (Basel) 1992;144:59-64.

25. Milam SB. Pathogenesis of degenerative temporomandibular joint arthritides. Odontology 2005;93:7-15.

26. Bergman AA, Heidger PM. Histology. Iowa City, IA: W.B. Saunders Company, 1996.

27. Symons NB. A histochemical study of the secondary cartilage of the mandibular condyle in the rat. Arch Oral Biol 1965;10:579-84.

28. Shen G, Darendeliler MA. The adaptive remodeling of condylar cartilage: a transition from chondrogenesis to osteogenesis. J Dent Res 2005;84:691-9.

29. Garant P. Oral cells and tissues. New Malden, Surrey, UK: Quintessence Publishing Co. Ltd., 2003.

30. Luyten FP. A scientific basis for the biologic regeneration of synovial joints. Oral Surg Oral Med Oral Pathol Oral Radiol Endod 1997;83:167-9.

31. Cotran R, Kumar V, Collins T. Pathologic basis of disease. Philadelphia: W.B. Saunders Company, 1999.

32. Meikle MC. Remodeling the dentofacial skeleton: the biological basis of orthodontics and dentofacial orthopedics. J Dent Res 2007;86:12-24.

33. Zarb GA, Carlsson GE. Temporomandibular disorders: osteoarthritis. J Orofac Pain 1999;13:295-306.

34. Thomas NR, Peyton SC. An electromyographic study of mastication in the freely moving rat. Arch Oral Biol 1983;28:939-45. 
35. Hinton RJ, Carlson DS. Response of the mandibular joint to loss of incisal function in the rat. Acta Anat (Basel) 1986;125:145-51.

36. Hinton RJ. Effect of altered masticatory function on [3H]thymidine and [35S]-sulfate incorporation in the condylar cartilage of the rat. Acta Anat (Basel) 1988;131:136-9.

37. Bouvier M. Effects of age on the ability of the rat temporomandibular joint to respond to changing functional demands. J Dent Res 1988;67:1206-12.

38. Ravosa MJ, Kunwar R, Stock SR, Stack MS. Pushing the limit: masticatory stress and adaptive plasticity in mammalian craniomandibular joints. J Exp Biol 2007;210: 628-41.

39. Kiliaridis S, Thilander B, Kjellberg H, Topouzelis N, Zafiriadis A. Effect of low masticatory function on condylar growth: a morphometric study in the rat. Am J Orthod Dentofacial Orthop 1999;116:121-5.

40. Pirttiniemi P, Kantomaa T, Salo L, Tuominen M. Effect of reduced articular function on deposition of type I and type II collagens in the mandibular condylar cartilage of the rat. Arch Oral Biol 1996;41:127-31.

41. Pirttiniemi P, Kantomaa T, Sorsa T. Effect of decreased loading on the metabolic activity of the mandibular condylar cartilage in the rat. Eur J Orthod 2004;26:1-5.

42. Sato I, Uneno R, Miwa Y, Sunohara M. Distribution of tenascin-C and tenascin-X, apoptotic and proliferating cells in postnatal soft-diet rat temporomandibular joint (TMJ). Ann Anat 2006;188:127-36.

43. De Boever JA, Keersmaekers K. Trauma in patients with temporomandibular disorders: frequency and treatment outcome. J Oral Rehabil 1996;23:91-6.

44. Carroll LJ, Ferrari R, Cassidy JD. Reduced or painful jaw movement after collision-related injuries: a populationbased study. J Am Dent Assoc 2007;138:86-93.

45. Sale H, Isberg A. Delayed temporomandibular joint pain and dysfunction induced by whiplash trauma: a controlled prospective study. J Am Dent Assoc 2007;138:1084-91.

46. Abubaker AO, Raslan WF, Sotereanos GC. Estrogen and progesterone receptors in temporomandibular joint discs of symptomatic and asymptomatic persons: a preliminary study. J Oral Maxillofac Surg 1993;51: 1096-100.

47. Milam SB, Aufdemorte TB, Sheridan PJ, Triplett RG, Van Sickels JE, Holt GR. Sexual dimorphism in the distribution of estrogen receptors in the temporomandibular joint complex of the baboon. Oral Surg Oral Med Oral Pathol 1987;64:527-32.

48. Aufdemorte TB, Van Sickels JE, Dolwick MF, Sheridan PJ, Holt GR, Aragon SB, et al. Estrogen receptors in the temporomandibular joint of the baboon (Papio cynocephalus): an autoradiographic study. Oral Surg Oral Med Oral Pathol 1986;61:307-14.

49. Yamada K, Nozawa-Inoue K, Kawano Y, Kohno S, Amizuka N, Iwanaga T, et al. Expression of estrogen receptor alpha (ER alpha) in the rat temporomandibular joint. Anat Rec Part A: Discov Mol Cell Evol Biol 2003;274:934-41.

50. Wang WHT, Chen C, Kapila S. Relaxin and estrogen receptor expression in TMJ and knee fibrocartilages. J Dent Res 2006;85:0021(abstract).
51. LeResche L, Saunders K, Von Korff MR, Barlow W, Dworkin SF. Use of exogenous hormones and risk of temporomandibular disorder pain. Pain 1997;69:153-60.

52. Meisler JG. Chronic pain conditions in women. J Womens Health 1999;8:313-20.

53. Landi N, Lombardi I, Manfredini D, Casarosa E, Biondi K, Gabbanini M, et al. Sexual hormone serum levels and temporomandibular disorders: a preliminary study. Gynecol Endocrinol 2005;20:99-103.

54. Kang SC, Lee DG, Choi JH, Kim ST, Kim YK, Ahn HJ. Association between estrogen receptor polymorphism and pain susceptibility in female temporomandibular joint osteoarthritis patients. Int J Oral Maxillofac Surg 2007;36:391-4.

55. Lee DG, Kim TW, Kang SC, Kim ST. Estrogen receptor gene polymorphism and craniofacial morphology in female TMJ osteoarthritis patients. Int J Oral Maxillofac Surg 2006;35:165-9.

56. Kapila S, Xie Y. Targeted induction of collagenase and stromelysin by relaxin in unprimed and beta-estradiolprimed diarthrodial joint fibrocartilaginous cells but not in synoviocytes. Lab Invest 1998;78:925-38.

57. Naqvi T, Duong TT, Hashem G, Shiga M, Zhang Q, Kapila S. Relaxin's induction of metalloproteinases is associated with the loss of collagen and glycosaminoglycans in synovial joint fibrocartilaginous explants. Arthritis Res Ther 2005;7:R1-11.

58. Wang W, Hayami T, Kapila S. Estrogen and relaxin induce while progesterone represses MMP expression in TMJ fibrochondrocytes. J Dent Res 2007;86:1279(abstract).

59. Birkedal-Hansen H, Moore WG, Bodden MK, Windsor LJ, Birkedal-Hansen B, DeCarlo A, et al. Matrix metalloproteinases: a review. Crit Rev Oral Biol Med 1993;4:197-250.

60. Visse R, Nagase H. Matrix metalloproteinases and tissue inhibitors of metalloproteinases: structure, function, and biochemistry. Circ Res 2003;92:827-39.

61. Hashem G, Zhang Q, Hayami T, Chen J, Wang W, Kapila $\mathrm{S}$. Relaxin and beta-estradiol modulate targeted matrix degradation in specific synovial joint fibrocartilages: progesterone prevents matrix loss. Arthritis Res Ther 2006; 8:R98.

62. Rintala M, Metsaranta M, Saamanen AM, Vuorio E, Ronning O. Abnormal craniofacial growth and early mandibular osteoarthritis in mice harbouring a mutant type II collagen transgene. J Anat 1997;190(Pt 2):201-8.

63. Lam NP, Li Y, Waldman AB, Brussiau J, Lee PL, Olsen $\mathrm{BR}$, et al. Age-dependent increase of discoidin domain receptor 2 and matrix metalloproteinase 13 expression in temporomandibular joint cartilage of type IX and type XI collagen-deficient mice. Arch Oral Biol 2007;52: 579-84.

64. Wadhwa S, Embree MC, Kilts T, Young MF, Ameye LG. Accelerated osteoarthritis in the temporomandibular joint of biglycan/fibromodulin double-deficient mice. Osteoarthritis Cartilage 2005;13:817-27.

65. Xu L, Flahiff CM, Waldman BA, Wu D, Olsen BR, Setton LA, et al. Osteoarthritis-like changes and decreased mechanical function of articular cartilage in the joints of mice with the chondrodysplasia gene (cho). Arthritis Rheum 2003;48:2509-18. 
66. Ameye L, Aria D, Jepsen K, Oldberg A, Xu T, Young MF. Abnormal collagen fibrils in tendons of biglycan/ fibromodulin-deficient mice lead to gait impairment, ectopic ossification, and osteoarthritis. FASEB J 2002;16: 673-80.

67. Bi Y, Stuelten CH, Kilts T, Wadhwa S, Iozzo RV, Robey PG, et al. Extracellular matrix proteoglycans control the fate of bone marrow stromal cells. J Biol Chem 2005; 280:30481-9.

68. Greess H, Anders K. [Indications for validity of computed tomography and magnetic resonance imaging of the temporomandibular joint]. Rontgenpraxis 2005;56:1-11.

69. Takaku S, Sano T, Yoshida M, Toyoda T. A comparison between magnetic resonance imaging and pathologic findings in patients with disc displacement. J Oral Maxillofac Surg 1998;56:171-6; discussion 177

70. Hintze H, Wiese M, Wenzel A. Cone beam CT and conventional tomography for the detection of morphological temporomandibular joint changes. Dentomaxillofac Radiol 2007;36:192-7.

71. Meng JH, Zhang WL, Liu DG, Zhao YP, Ma XC. [Diagnostic evaluation of the temporomandibular joint osteoarthritis using cone beam computed tomography compared with conventional radiographic technology]. Beijing Da Xue Xue Bao 2007;39:26-9.

72. Honda K, Larheim TA, Maruhashi K, Matsumoto K, Iwai $\mathrm{K}$. Osseous abnormalities of the mandibular condyle: diagnostic reliability of cone beam computed tomography compared with helical computed tomography based on an autopsy material. Dentomaxillofac Radiol 2006;35: $152-7$.

73. Hilgers ML, Scarfe WC, Scheetz JP, Farman AG. Accuracy of linear temporomandibular joint measurements with cone beam computed tomography and digital cephalometric radiography. Am J Orthod Dentofacial Orthop 2005;128:803-11.

74. Honda K, Bjornland T. Image-guided puncture technique for the superior temporomandibular joint space: value of cone beam computed tomography (CBCT). Oral Surg Oral Med Oral Pathol Oral Radiol Endod 2006;102:281-6.

75. van Dijke CF, Kirk BA, Peterfy CG, Genant HK, Brasch RC, Kapila S. Arthritic temporomandibular joint: correlation of macromolecular contrast-enhanced MR imaging parameters and histopathologic findings. Radiology 1997;204:825-32.

76. Tominaga K, Habu M, Sukedai M, Hirota Y, Takahashi T, Fukuda J. IL-1 beta, IL-1 receptor antagonist, and soluble type II IL-1 receptor in synovial fluid of patients with temporomandibular disorders. Arch Oral Biol 2004:49:493-9.

77. Kubota E, Imamura H, Kubota T, Shibata T, Murakami $\mathrm{K}$. Interleukin 1 beta and stromelysin (MMP3) activity of synovial fluid as possible markers of osteoarthritis in the temporomandibular joint. J Oral Maxillofac Surg 1997;55:20-7; discussion 27-8.

78. Shafer DM, Assael L, White LB, Rossomando EF. Tumor necrosis factor-alpha as a biochemical marker of pain and outcome in temporomandibular joints with internal derangements. J Oral Maxillofac Surg 1994;52:786-91; discussion 791-2.
79. Srinivas R, Sorsa T, Tjaderhane L, Niemi E, Raustia A, Pernu $\mathrm{H}$, et al. Matrix metalloproteinases in mild and severe temporomandibular joint internal derangement synovial fluid. Oral Surg Oral Med Oral Pathol Oral Radiol Endod 2001;91:517-25.

80. Yoshida K, Takatsuka S, Hatada E, Nakamura H, Tanaka A, Ueki K, et al. Expression of matrix metalloproteinases and aggrecanase in the synovial fluids of patients with symptomatic temporomandibular disorders. Oral Surg Oral Med Oral Pathol Oral Radiol Endod 2006;102:22-7.

81. Miyamoto K, Ishimaru J, Kurita K, Goss AN. Synovial matrix metalloproteinase-2 in different stages of sheep temporomandibular joint osteoarthrosis. J Oral Maxillofac Surg 2002;60:66-72.

82. Tanaka A, Kumagai S, Kawashiri S, Takatsuka S, Nakagawa K, Yamamoto E, et al. Expression of matrix metalloproteinase-2 and -9 in synovial fluid of the temporomandibular joint accompanied by anterior disc displacement. J Oral Pathol Med 2001;30:59-64.

83. Yoshida K, Takatsuka S, Tanaka A, Hatada E, Nakamura $\mathrm{H}$, Nakagawa K, et al. Aggrecanase analysis of synovial fluid of temporomandibular joint disorders. Oral Diseases 2005;11:299-302.

84. Aghabeigi B, Cintra N, Meghji S, Evans A, Crean SJ. Temporomandibular joint synovial fluid sampling: estimation of dilution factor using calcium ion concentration. Int $\mathbf{J}$ Oral Maxillofac Surg 2002;31:646-9.

85. Sato J, Segami N, Nishimura M, Yoshitake Y, Kaneyama $\mathrm{K}$, Kitagawa Y. Expression of interleukin 8 in synovial tissues in patients with internal derangement of the temporomandibular joint and its relationship with clinical variables. Oral Surg Oral Med Oral Pathol Oral Radiol Endod 2007;103:467-74.

86. Sato J, Segami N, Nishimura M, Yoshimura H, Demura N, Yoshitake Y, et al. Correlation between the arthroscopic diagnosis of synovitis and microvessel density in synovial tissues in patients with internal derangement of the temporomandibular joint. J Craniomaxillofac Surg 2003;31:101-6.

87. Tanimoto K, Ohno S, Imada M, Honda K, Ohno-Nakahara M, Kapila S, et al. Utility of urinary pyridinoline and deoxypyridinoline ratio for diagnosis of osteoarthritis at temporomandibular joint. J Oral Pathol Med 2004;33:218-23

88. McGregor NR, Zerbes M, Niblett SH, Dunstan RH, Roberts TK, Butt HL, et al. Pain intensity, illness duration, and protein catabolism in temporomandibular disorder patients with chronic muscle pain. J Orofac Pain $2003 ; 17: 112-24$

89. Landi N, Manfredini D, Lombardi I, Casarosa E, Bosco M. 17-beta-estradiol and progesterone serum levels in temporomandibular disorder patients. Minerva Stomatol 2004;53:651-60.

90. Nordahl S, Alstergren P, Eliasson S, Kopp S. Radiographic signs of bone destruction in the arthritic temporomandibular joint with special reference to markers of disease activity: a longitudinal study. Rheumatology (Oxford) 2001;40:691-4.

91. Marshall KW, Zhang H, Yager TD, Nossova N, Dempsey A, Zheng R, et al. Blood-based biomarkers for detecting 
mild osteoarthritis in the human knee. Osteoarthritis Cartilage 2005;13:861-71.

92. Michalowicz BS, Pihlstrom BL, Hodges JS, Bouchard TJ Jr. No heritability of temporomandibular joint signs and symptoms. J Dent Res 2000;79:1573-8.

93. Ojima K, Watanabe N, Narita N, Narita M. Temporomandibular disorder is associated with a serotonin transporter gene polymorphism in the Japanese population. Biopsychosoc Med 2007;1:3.

94. Diatchenko L, Anderson AD, Slade GD, Fillingim RB, Shabalina SA, Higgins TJ, et al. Three major haplotypes of the beta 2 adrenergic receptor define psychological profile, blood pressure, and the risk for development of a common musculoskeletal pain disorder. Am J Med Genet Part B: Neuropsychiatr Genet 2006;141:449-62.

95. Wolford LM. Temporomandibular joint devices: treatment factors and outcomes. Oral Surg Oral Med Oral Pathol Oral Radiol Endod 1997;83:143-9.

96. Ta LE, Phero JC, Pillemer SR, Hale-Donze H, McCartney-Francis N, Kingman A, et al. Clinical evaluation of patients with temporomandibular joint implants. J Oral Maxillofac Surg 2002;60:1389-99.

97. Kapila S, King GE, eds. Conferences on Orthodontics Advances in Science and Technology (COAST) Foundation's Second Biennial Symposium: Craniofacial Skeletal Bioengineering. Orthod Craniofac Res 2005;8(4).
98. King G, Kapila SE, eds. Conferences on Orthodontic Advances in Science and Technology (COAST) Foundation's Second Biennial Symposium: Craniofacial Skeletal Bioengineering. Orthod Craniofac Res 2005;8(3).

99. Bailey MM, Wang L, Bode CJ, Mitchell KE, Detamore MS. A comparison of human umbilical cord matrix stem cells and temporomandibular joint condylar chondrocytes for tissue engineering temporomandibular joint condylar cartilage. Tissue Eng 2007;13(8):2003-10.

100. Schek RM, Taboas JM, Hollister SJ, Krebsbach PH. Tissue engineering osteochondral implants for temporomandibular joint repair. Orthod Craniofac Res 2005;8:313-9.

101. Mao JJ, Giannobile WV, Helms JA, Hollister SJ, Krebsbach PH, Longaker MT, et al. Craniofacial tissue engineering by stem cells. J Dent Res 2006;85:966-79.

102. Alhadlaq A, Mao JJ. Tissue-engineered neogenesis of human-shaped mandibular condyle from rat mesenchymal stem cells. J Dent Res 2003;82:951-6.

103. Smith MH, Flanagan CL, Kemppainen JM, Sack JA, Chung H, Das S, et al. Computed tomography-based tissue-engineered scaffolds in craniomaxillofacial surgery. Int J Med Robotics Comput Assisted Surg 2007;3(3):207-16. 